\title{
Development of a Sensor Based Self Powered Smart Control System for Agricultural Irrigation Systems
}

\author{
A.H.M.N. Chamara*, K.C.R. Perera, R. Amarasinghe, W.S.D. Nandika
}

\begin{abstract}
Precision agriculture is combined with irrigation control systems to observe the environment and respond accordingly. In this paper, we discussed developmental procedure of a novel irrigation control system called Sensor Based Self-powered Smart Irrigation Control System (SSSICS). In the current market, there are several irrigation controllers available and they are either timer based open loop (OL) or sensor-based closed loop (CL) irrigation controllers. Each method has different advantages and disadvantages, and SSSICS contains OL and CL control techniques to get rid of disadvantages. We used OL control technique to work in the Timer Mode(TM) and CL control technique to work in the Intelligent Mode (IM). We introduced a new graphical user interface (GUI) as a human-machine interface (HMI). This HMI and available inputs facilitated the farmer to set precise environmental parameters required for the crop to give maximum yield. For remote farm fields, it is necessary to have a remote communication (RC) and uninterrupted power supply. Text messages that receive and send via Global System for Mobile (GSM) Communication allow the farmer/user to perform RC with the control system (CS) of the SSSICS. We designed a Micro Hydro Power Generator (MHPG) array and solar system including rechargeable batteries to give the power required to the SSSICS. The SSSICS was tested in real environment and it was demonstrated that hybrid power generation concept by incorporating open loop and closed loop control techniques works properly in the hardware platform developed for the study.
\end{abstract}

Keywords: Closed loop, Micro hydro power generator, Open loop, Remote communication, Self-powered, Smart irrigation control system

Department of Mechanical Engineering, Faculty of Engineering, University of Moratuwa, Sri Lanka *nipunachamara@live.com

\section{INTRODUCTION}

Irrigation control systems are required for water management of the agricultural crops. This is because water should be provided to the crops in optimum amounts to garner the harvest with the best quality and the maximum yield. In the wine industry, grapes are grown in controlled irrigation conditions such as deficit irrigation to bring about the quality of the grapes which caters to the taste of the wine (Leeuwen et al, 2009). Water productivity (WP) is the ratio of net benefits from the crop, forestry, fishery, livestock and mixed agricultural systems to the amount of water used to produce those benefits. Sri Lanka is a country which depends heavily on rainwater for agricultural purposes and having an advanced rain water harvesting system and distribution system called "wewa" (man-made water reservoirs) and "Ela" (man-made channels). Population increment, change of weather patterns and the increasing cost of labor have become common issues of agriculture in Sri Lanka during past decades (Jayasekera et al, 2011). During the last century, different types of modern irrigation systems were introduced to Sri Lanka and they are being practiced now in most of the regions in Sri Lanka. Typical irrigation systems in use are localized irrigation, drip irrigation and sprinkler irrigation (Centers for Disease Control and Prevention, 2013) However, very few number of irrigation controllers are in use due to difficulty of operating them in real environment. However, high WP plays a key role in Sri Lankan agriculture, hence automatic irrigation controllers are 
the best solution to gain high WP (Molden, 2010)

Irrigational control techniques (CT) can be predominantly classified as open-loop (OL) irrigation controllers and closed-loop (CL) irrigation controllers. The OL irrigation CSs take no feedback on the environmental factors of the crop and the irrigation is performed according to the watering periods which are predefined by the user. Usually, the parameters which need presetting are the length of the irrigation period, length of the interval between two irrigation periods and the amount of water discharged. The CL irrigation CSs obtain the feedback of necessary data to determine the water quantity required for the crops. There are several parameters such as temperature, humidity and soil moisture and water evaporation amount from the ground, which should be defined according to the nature of the crop grown (Hanson, et al, 2000).

There are commercially available irrigation CS which uses both OL and CL control techniques (Rainbird, 2012). The open loop irrigation controlling is performed according to the predefined time periods and intervals and the closed loop irrigation controlling is performed by discharging the water to the crops by acquiring the measured feedbacks on the conditions of the crop from the sensor system which consists of a leaf sensor, rain sensor, and a temperature sensor. RainBird (Rainbird, 2012) provides the capability of remote controllability to the farmer by the integrated GSM communication system, where the system can be operated by a GSM-based mobile phone. Nano Ganesh is an industrially used open loop irrigational control system, which is remotely operated by the farmer's telecommunication device. It uses the GSM communication system and it can receive text messages from the farmer who feeds the irrigational system with the information about the irrigation time periods, intervals of irrigation. . Then the Nano Ganesh device activates the irrigation system appropriately (Nanoganesh, 2012). Rural areas of Sri Lanka like Kalpitiya peninsula, where very intensive agricultural methods are practiced do not even have a suitable electric supply to power up the irrigation controller. Therefore, it was a necessity to find a solution for power up the controller without the support of the main electric grid. In some places, where greenhouses are used, farm managers are expected to gather more data about the field during a short time and they need to analyze them in a short time to reach to a conclusion.

This research was focused to develop an integrated, sustainable irrigation control system which is more user friendly and smarter than the existing control systems using existing and compatible technologies.

\section{MATERIALS AND METHODS}

The development of the sssics was based on fulfilling the following tasks.

- Sensing - Development of the sensor system with appropriate sensors which can forecast the water requirement of the crop.

- Processing and analyzing Development of the algorithm for the control system for the CL irrigation controlling and OL irrigation controlling.

- Power generation - Development of the hybrid power generation system to satisfy the power requirement of the main control unit, sensor system, and the GSM communication system.

- Power management - Development of the power management system to harvest the energy generated by the hybrid power generation system. 
- Flow controlling - Development of solenoid operated valve system, which can be controlled by the CS.

- Data communication - Development of GSM communication system and the GUI for the personal computer.

The aforementioned aspects were considered in the development of the sssics. The methodology in the development of the system is given below.

\section{Sensor System}

There are three main types of water available in the soil: gravitational water which is free water that moves through the soil due to the force of gravity and drains out within two or three days; capillary water which is in the micropores, and the soil solution; and hygroscopic water which is in the forms of very thin films around soil particles and is not available to the plant. The soil moisture sensor must measure the availability of gravitational water and capillary water which can be taken by the roots of the plants in the field (Brooms, 2012).

In order to measure the soil moisture in the crop root zone, YL69 soil moisture sensor was selected (Figure 3, A), which was a simple water sensor capable of measuring the soil water content. The soil moisture sensor was integrated with a signal conditioner circuit for the sensitivity adjustments (Figure 2). This helps to adjust the sensitivity for different soil types. To decide the temperature of the environment in the field we used an LM35 temperature sensor (Figure 3, B) (Texas Instruments, 2012)

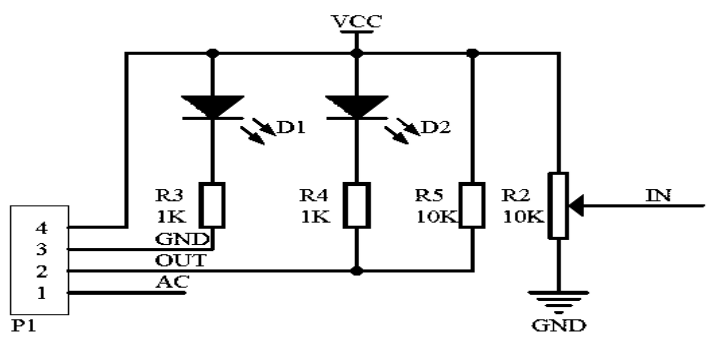

Figure 1: Circuit configuration of the soil moisture sensor

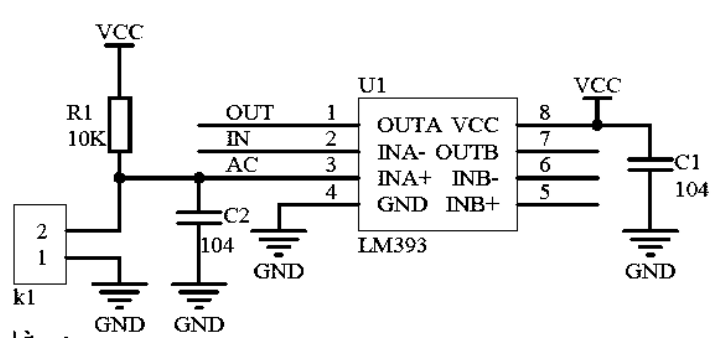

Figure 2: Circuit configuration of the sensitivity adjuster

\section{Main Control System}

The main control system is a CL system and consists (Programmable Integrated Circuit) PIC microcontroller (Figure 3, C) which controls the four subsystems including sensors, actuator outputs, GUI and GSM module. The main idea of having the PIC based CS was to interconnect various other controlling units at low cost. Programming of the PIC microcontroller was done by $\mathrm{C}$ programming language through mikroC PRO for PIC, compiler which was a fullfeatured C compiler for PIC devices. A GSM (Global System for Mobile Communication) (Figure 3, E) module connected through the serial port while a computer was connected with USB (Universal Serial Bus) connection (Figure 3 , I). All the readings from the sensors were converted to digital values by the ADC (Analog Digital Converter) unit in PIC and the outputs to the actuators are decided via the PIC as programmed or the 


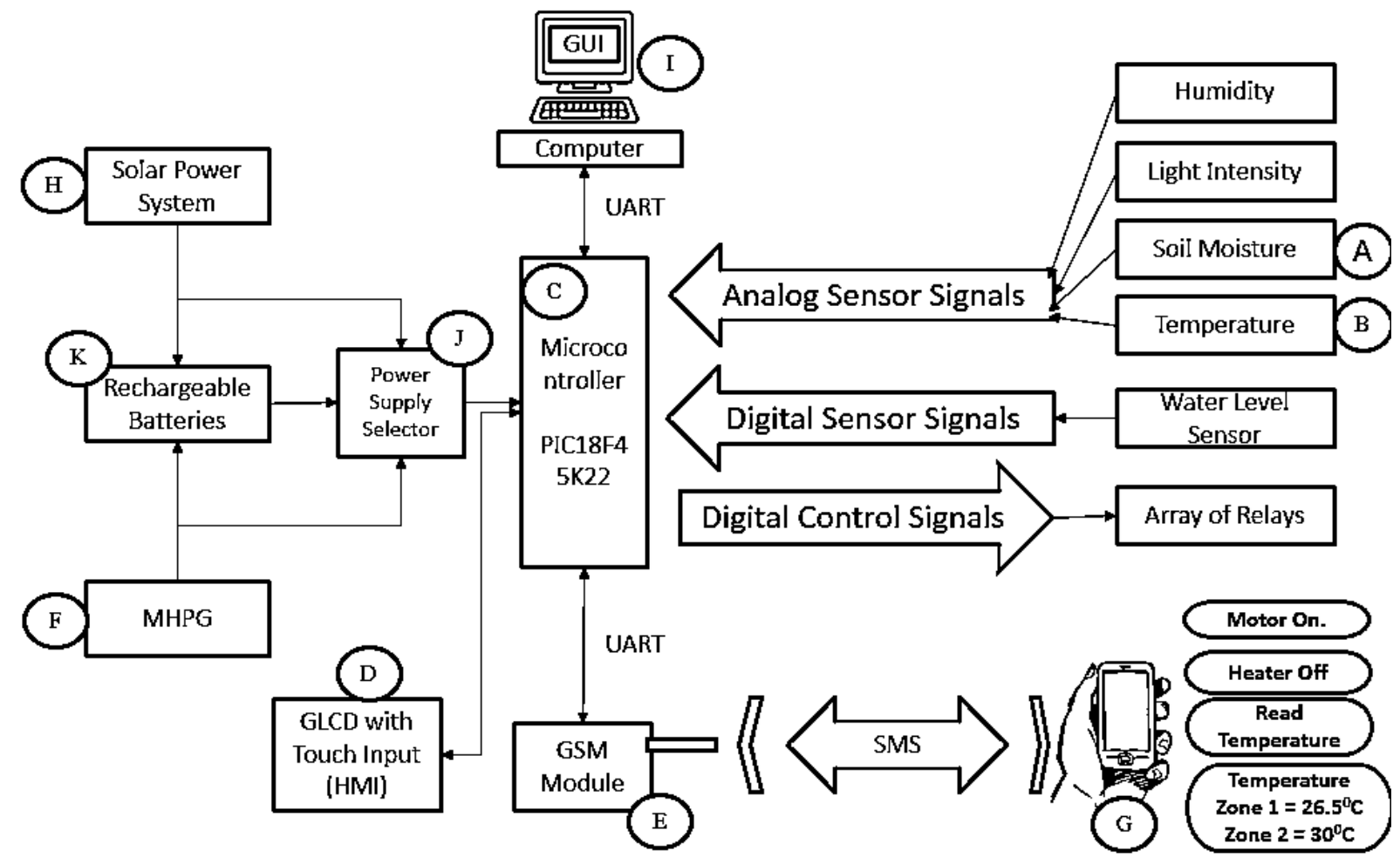

Figure 3: Schematic diagram of SSSICS
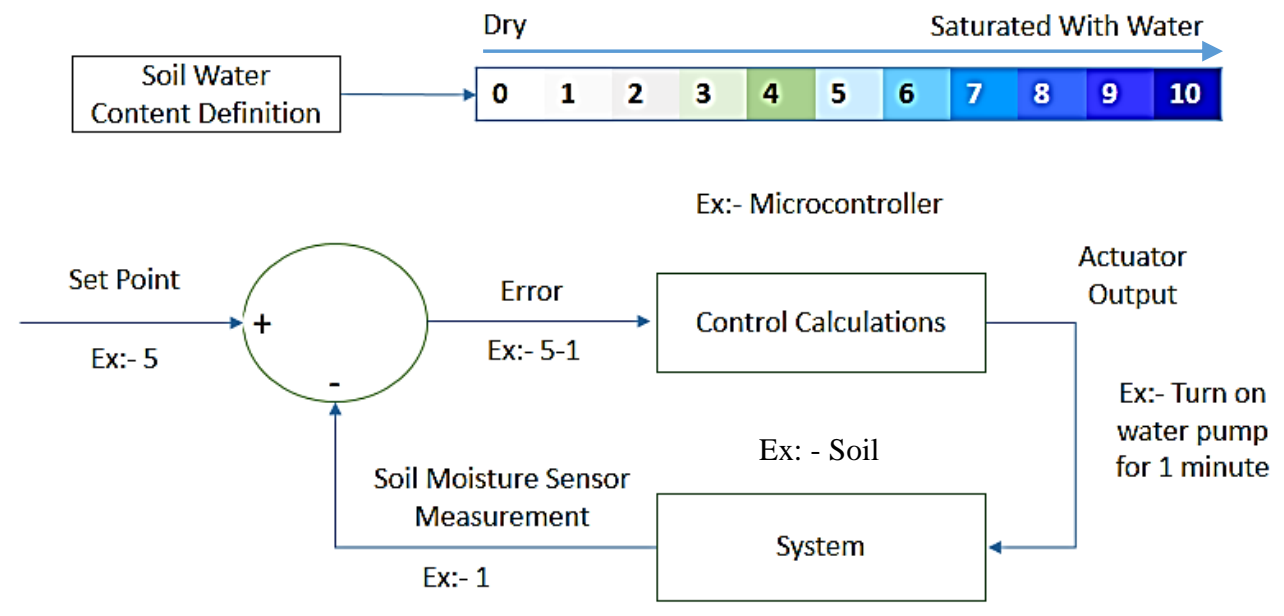

Figure 4: Closed loop control block diagram for soil water content controlling

user-defined variable via simply control system human interface, computer GUI or the GSM feedback from the user.

Components of the main control system (Figure 3) comprise of PIC 18F45K22 microcontroller, touch input Graphical Liquid Crystal Display (GLCD) and communication ports and power supply port (Microchip Technology Inc, 2012). The control algorithm for the intelligent mode and the timer mode developed as follows.

\section{Intelligent Mode}

Intelligent irrigation is where the irrigation is performed after measuring the 
environmental conditions of the plant, i.e. temperature, humidity, soil moisture and light from the sensor system .This system is a closed loop system. By taking that data as inputs to the control system, the system compares the sensor readings with the threshold values or Set Point as mentioned in the Figure 4, provided by the user. If the temperature is more than the threshold values, the decision is made to turn on the fans. If the humidity is less than the threshold values, the decision is made to turn on the mist makers. Since the decisions are made based on the sensor feedback, the intelligent mode follows the CL controlling technique. (Figure 4) Then after the sensors have come to their threshold values which are defined by the user, the MCU provides another signal to the solenoid valve to stop the fans or mist makers.

The threshold values for the temperature sensor, humidity sensor, and the soil moisture sensor can be adjusted by the farmer according to the plant type, plant stage in the life cycle, the type of soil of the agricultural field and the climate.

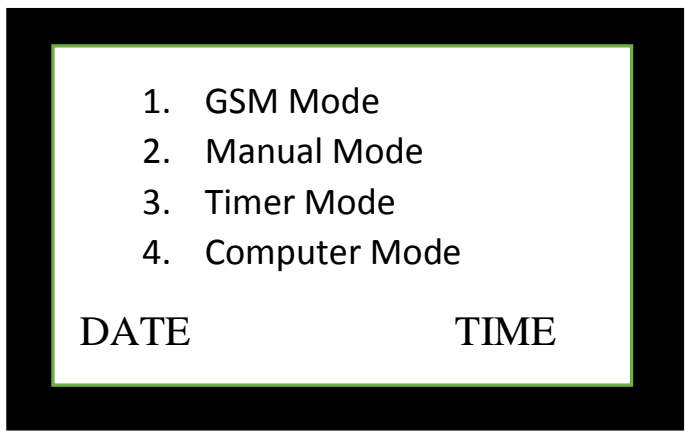

Figure 5 Human machine interface home screen (HMI)

\section{Timer Mode}

In the TM, the SSSICS provids irrigation intervals and irrigation time periods for the user to choose. Moreover, these irrigation time intervals and time periods can be preprogrammed according to the crop type and stage of the life cycle of the crop; because the amount of water needed is dependent on the crop type and the stage of the life cycle of the crop (Figure 6). Since there are no feedbacks taken in this mode, the TM follows the open loop control technique.

\section{Graphical User Input}

The GUI designed as the software in the computer connected to the CS (Figure 3, I) behaves as the platform for data communication between the user and the control system.
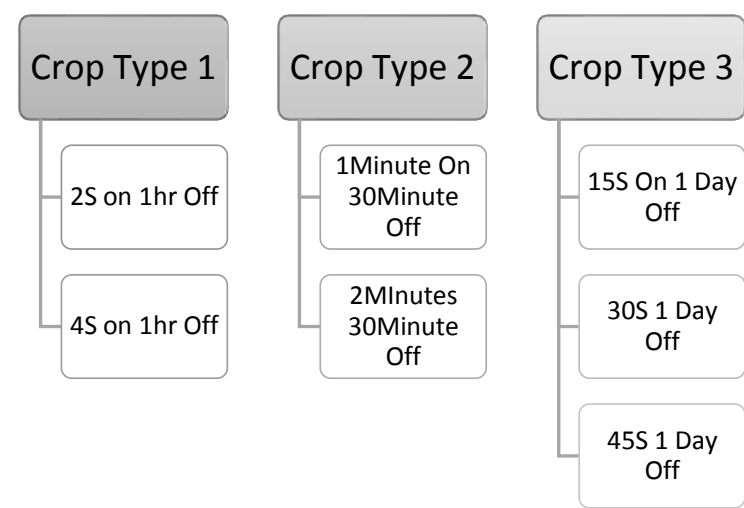

Figure 6 Timer mode possible timer value set up

The GUI has the functionalities of inputting threshold crop temperature, soil moisture and display the real- time plotting of the crop environment temperature and the soil moisture and the feeding data to the GSM communication system sent through the farmer's mobile phone (Figure 3, G). The irrigation control system has a touch input (Figure 5). Graphical Liquid Crystal Display (GLCD) is used to select the irrigation mode (intelligent mode/timer mode) and GLCD also provides the output information about the sensor feedbacks on crop temperature and the crop soil moisture. Moreover the control system is connected to a computer through Universal Asynchronous Receiver/Transmitter (UART) serial communication using RS 
232 communication protocol, where the control system can be operated by the GUI developed using Visual Basic (Figure 7).

\section{Hybrid Power System}

The power requirement for the system is satisfied by the hybrid power generation

\section{Solenoid Valve}

The solenoid valve will be automatically operated by the signal provided by the MCU. The valve is DC operated, where the power is utilized from the rechargeable battery pack through the main control unit.

Compared to RainBird and Nano

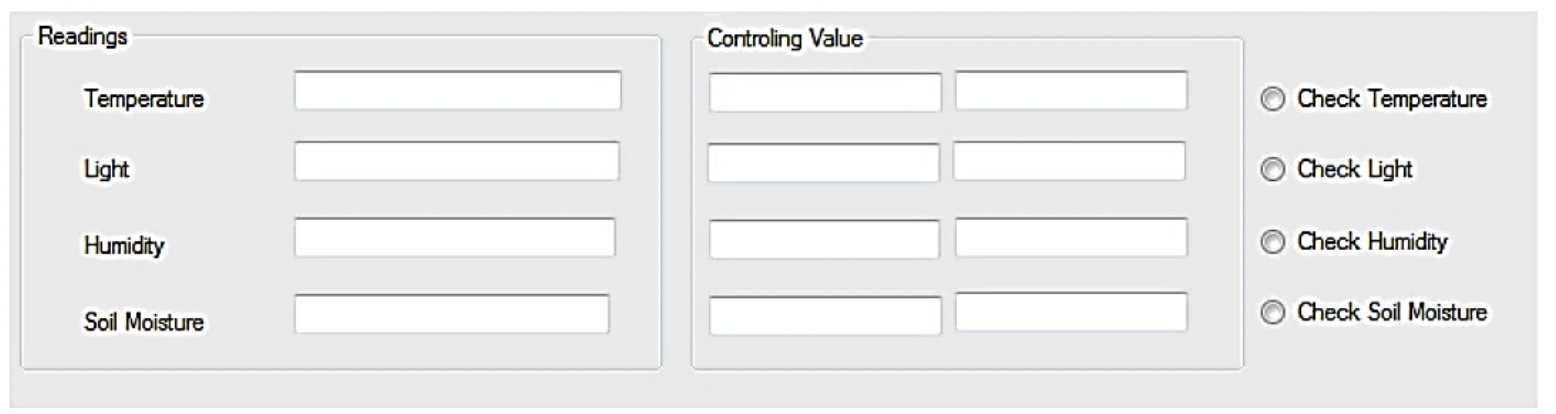

Figure 7: Graphical user input

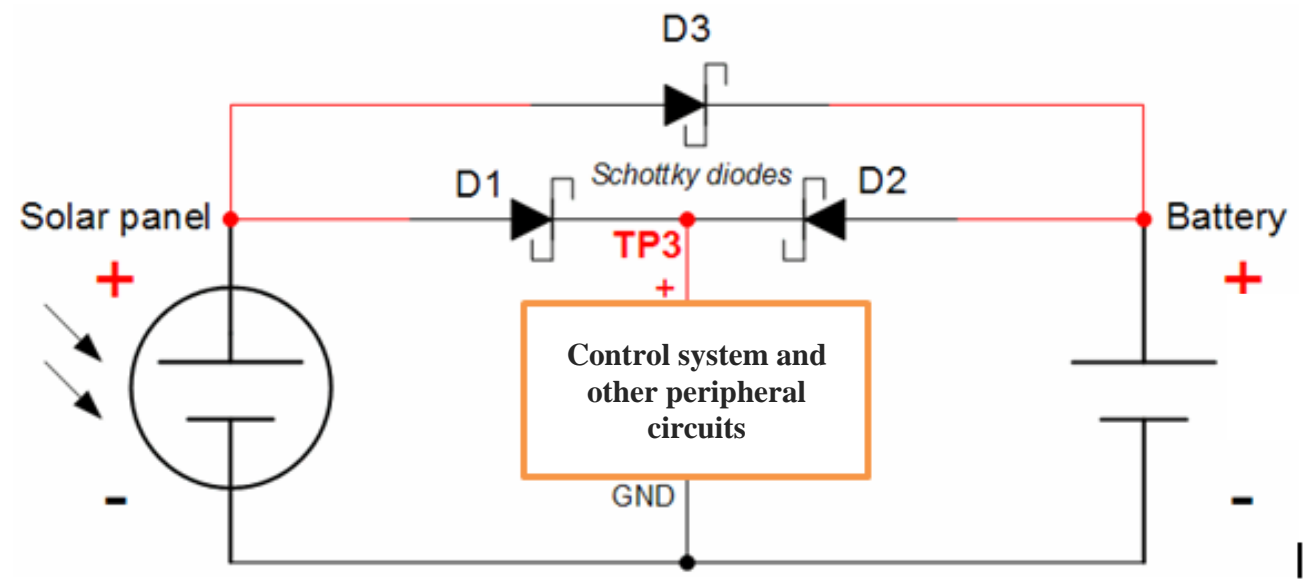

Figure 8: Power supply selector

system, which consists of the $3.6 \mathrm{~V}$ micro hydropower generator (MHPG) (Figure 3, F) and the $12 \mathrm{~V}$ solar panel (Figure 3, H). The power supply selector (Figure 8) optimally direct the power generated in order to harvest the energy generated in 250mAh Ni-MH (Figure 3, K) rechargeable batteries. The power supply selector (Figure 3, J) comprises of LM 2587 DC power step-up voltage regulator to increase the voltage generated by the MHPG and solar-micro hydro power manipulator.
Ganesh control systems, the SSSICS has the advantage of controlling the irrigation by providing the exact amount of water to the plants through real-time monitoring with the sensor system. In addition, the system includes a self-power system which is very appropriate for agricultural fields where the system independently works out without any external power source. Therefore SSSICS is a better solution for rural areas where electricity is not available in Sri Lanka. 


\section{RESULTS AND DISCUSSION}

The fabrication of SSSICS was performed, first with the fabrication of the subsystems and then the four subsystems were assembled together to fully function the total system. The results of each subsystem are presented in the following subsections in the event of their research and development and the Computer Aided Design done by Solidworks 2010 of the final system is shown in the Figure 10.

\section{Control System}

Selected PIC 18f45K22 Microcontroller clock speed has no issue with handling 20 analog inputs at the demonstrated system with 10 digital outputs. In the SSSICS designed control unit included only the parameters of soil moisture and field temperature but the CS was able to connect with light, air humidity, gas and flow sensors with suitable signal conditioning. Actuator system consisted of pump and solenoid valves but the SSSICS was able to interface with different types of actuators through the relay system.

\section{GSM Communication System}

The GSM communication system was connected to the microcontroller directly and text messages were sent and received from the mobile device of the user. Usually, the GSM module is connected through a computer to the microcontroller, but we have used the microcontroller based SMS gateway method for the direct connection with the microcontroller. This method of direct connection with the microcontroller is elaborately discussed in the present paper.

\section{Self-power System}

Two micro hydro turbine rotor designs were proposed for the micro hydro power generator of the self-power system, namely the horizontal axis impulse turbine and the horizontal axis reaction turbine. Figure 9 represents the flow vs voltage output of the micro hydro turbine used for self-power generation in SSSICS. For the micro hydro generator to work properly it required at least $3 \mathrm{l} / \mathrm{min}$ flow rate under given pressure to exceed the 3 voltage output. Following equation (Equation 1) was derived to find the number of MHPG required to power up a SSSICS and the MHPG can be connected in parallel circuit to harness more energy.

\section{CONCLUSION}

SSSICS tested in the real environment proved that hybrid power generation concept by incorporating open loop and closed loop control techniques worked without any issue in the developed hardware platform.

However, the HMI sensitivity was not enough and needed to connect a more sensitive and large display than the current one. In order to connect more than 20 number of sensors, this system needs to be developed further. Also, there is a possibility of connecting SSSICS with the weather forecast data and irrigate accordingly.

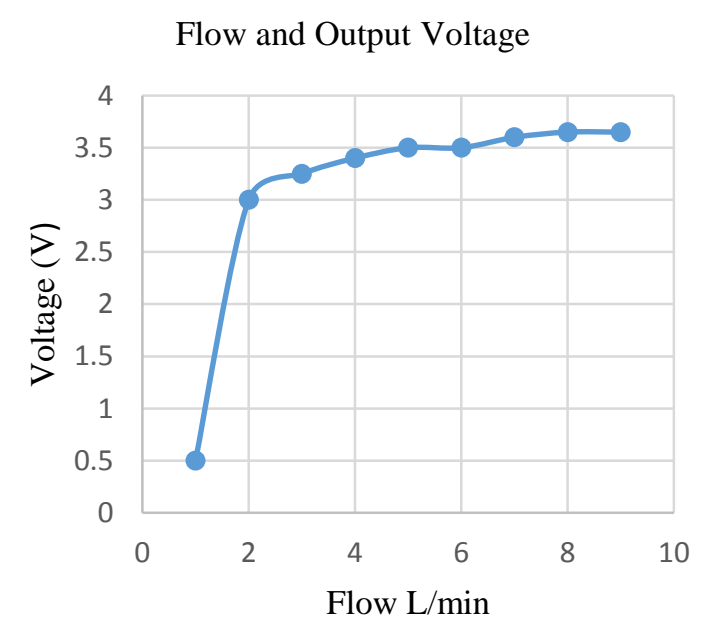

Figure 9: Flow vs. voltage output 
Power $=V . I=3.6[v] \times 0.3[A]=1[W] ; \quad$ maximum $P=V . I . n \quad ; \mathrm{n}$-Number of MHPGs

$P_{M H P G}=\sum_{i=1}^{n}$ V.I.t. $t_{i} \cdot k_{i}$

$t_{i}$ - the effective time of a solenoid valve open time

$k_{i}-$ number of water outlets which fix with an MHPG

\section{Equation 1}

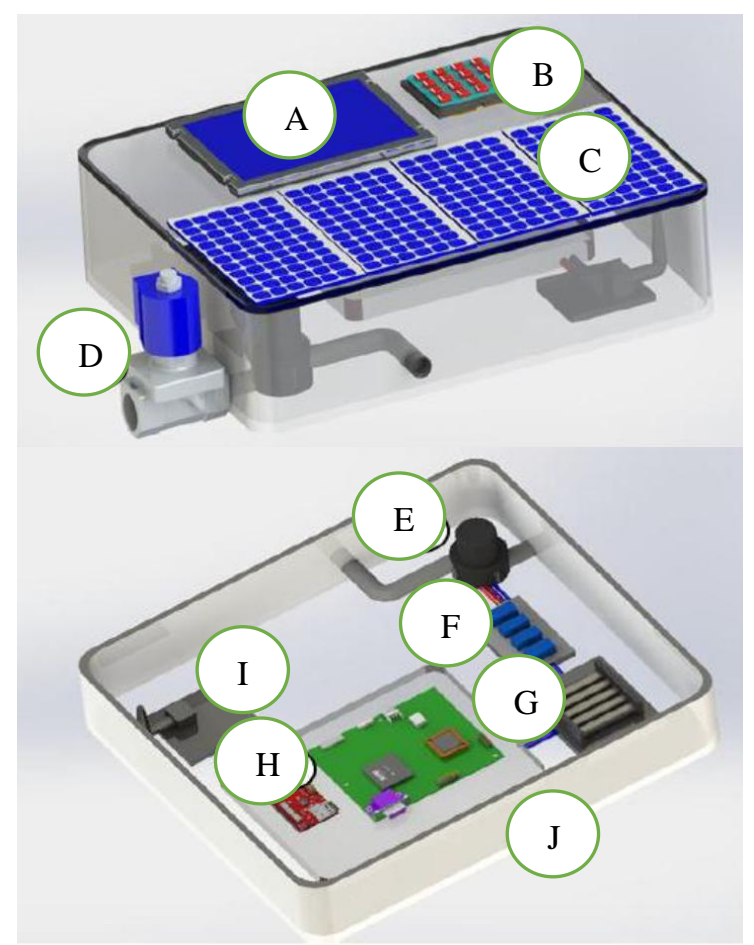
A. HMI
B. Key pad
C. Solar panels
D. Main solenoid valve
E. Single MHPG
F. Relay array
G. Rechargeable Batteries
H. Microcontroller and Signal
Conditioning Board
I. GSM module
J. Instrument Cover

Figure 10: Solidwork model of final product

\section{REFERENCES}

Brooms, S. W., (2012). Types of Soil Water. Available from: http://broome.soil.ncsu.edu/ssc012/ Lecture/topic9.htm

Centers for disease control and prevention, (2013). Types of agricultural water use., Irrigation vs. Rain-Fed Agriculture., [Online] Available at: https://www.cdc.gov/ Ganesh, N., 2012. Nano Ganesh C (Mobile Phone Model ), Nano Ganesh-GSM, Nano Ganesh M2M. [Online] Available at: http://www.nanoganesh.com/

Hanson, B., Orloff, S. and Peters, D. (2000). Monitoring soil moisture helps refine irrigation management. California Agriculture 54(3):3842.https://doi.org/10.3733/ca.v05 4n03p38.

Jayasekera, D. L., Kaluarachchi, J. J. and Villholth, K. G., (2011). Groundwater stress and vulnerability in rural coastal aquifers under competing demands: a case study from Sri Lanka. Environmental Monitoring and Assessment,176(1), 13-30.

Microchip Technology Inc., (2012). 28/40/44Pin, Low-Power, High-Performance Microcontrollers with XLP Technology. Available from: http://www.microchip.com

Leeuwen, C. V., Tregoat, O., Chone, X., Boise, B., Pernet, D and Gaudillere, J. P., Vol 43, No 3 (2009). Vine water status is a key factor in grape ripening and vintage quality for red Bordeaux wine. How can it be assessed for vineyard management purposes?. Journal international des sciences de la vigne et du vin,43(3): . 121-134. 
A.H.M.N. Chamara, K.C.R. Perera, R. Amarasinghe, W.S.D. Nandika

Molden, D., Oweis, T., Steduto, P., Bindraban, P., Hanjra, M.A. and Kijne, J., (2010). Improving agricultural water productivity: between optimism and caution. Agricultural Water Management, 97(4), pp.528-535.

Nanoganesh, (2012). Nano Ganesh C (Mobile Phone Model), Nano Ganesh-GSM, Nano Ganesh M2M. [Online] Available at: http://www.nanoganesh.com/

Rainbird, (2012). Product Informations. Available from: http://www.rainbird.com/

Texas Instruments., (2012). LM35 Precision Centigrade Temperature Sensors. Available from: http://www.ti.com/lit/ds/symlink/lm 35.pdf 